\title{
Design of Company's Salary Management System
}

\author{
Lei Xiong \\ College of Information Engineering, Jiangxi University of Technology, Jiangxi Nanchang
}

Keywords: Salary; Information management system; Database; Employees' file

\begin{abstract}
In order to improve efficiency of salary management and company's information level, this paper first analyzes limitations of salary management system, and then demands and feasibility and designs each functional module. Finally, it tests software. System designed in this paper has functional modules like user management, password management, employee management, payroll management and payroll query. The planning and promotion of this system can enable more people get to know internal information about this enterprise's employees through various channels, which on one hand can promote sales of products, on the other hand satisfies people's needs.
\end{abstract}

\section{Overview}

As "enterprise website" has huge impact on China's media, so there are a lot of relevant researches, and this paper mainly discusses opportunities and challenges in this industry that enterprises are faced with in corporate culture, timely activities, enterprises' services, users' services, planning and promotion of enterprises' brand image as well as countermeasures that enterprises take.

One, Researches of challenges faced by enterprises in planning and promoting their brand images in the context of "salary management system". In the environment of "salary management", it has become the main research object to master the development of both advantages of both business and channels.

Two, Research of opportunities faced by enterprises in planning and promoting their brand images in the context of "salary management system" as well as the countermeasures

"Salary management system" has important strategic significance. In planning and promoting brand images, enterprises should seize the opportunity and face challenges to actively formulate a series of corresponding policies while fostering strengths and circumventing weaknesses so as to improve their core competitiveness. There are a lot of people taking this as the research object.

It can be seen from the above research materials that it has become the focus of research for experts of this industry and other industries as well as media to vigorously develop "salary management system" to improve the overall strength of enterprises in China while planning and promoting enterprises' brand image. "Salary management system" is an irresistible trend, which is determined by various factors. However, few people mention the various difficulties in the concrete practice of facing this challenge in planning and promoting enterprises' brand image, so I will try to explore this for necessary supplement to defects of previous researches. 


\section{Analysis of this System}

Analysis of Demands. This system mainly publicizes company's images, updates relevant news in this industry, plans and promotes some products of the company and manages employees' salary as well as the company's website. Therefore, the following considerations should be made in terms of the website's function: the first is functions that manager need; the second is functions that the company's employees need; and the third is functions needed by administrators while adding employees' information and assessing their salary.

Operation of salary management system is divided into administrator's operation, including system management, employees' information management, and salary management, etc.

Feasibility Analysis. (1) Technical feasibility: currently, many software companies in China are engaged in developing and researching websites to provide reliable and feasible corporate management system for companies and units of various industries. Through the learning of programming language and basic courses during university time, existing programming software can be used to write suitable procurement management module.

(2) Economic feasibility: Roles and advantages of procurement modules have already been mentioned before - they can save costs for companies and increase their competitive advantages. Therefore, developing or using procurement modules in the corporate management system can bring huge profits to companies and the profits outdistance its development costs.

(3) Operational feasibility: according to the process and habits of departments that use it and from the operation ways or operation process, scheme that users can accept are used.

Analysis of System's Structure. Administrator's operation is divided by the salary management system as administrator's administration, password management, employees' file management, payroll management and payroll inquiry, etc.

Analysis of Administrator's Management

Companies' salary information management is the process that companies' administrators manage employees' information and companies' salary in order to achieve the company's goal. It is the company's advanced information technologies as a means of sorting, discovery, storage and use of the information process, information activities on the company's strategic planning process, elements in the information activities of planning, organizing, leading, controlling the decision-making process, strive for efficient allocation of resources, shared management, coordinated operation, with minimal cost to create the greatest benefit. Company information management is a form of information management, and information as a resource to be developed, and information as a corporate asset information and core.

Corporate information management is the management of company information, including company login information staff management, mainly for background operations changing the front page display contents.

Analysis of Password Modification Management

Password management is to maintain the company released the salary information, including employee information are added and deleted. Administrators can turn on the company's latest wage information for timely updates to the websites so as to make the staff quickly become aware of their personal wages.

Analysis of Employees' File Management

Primarily on fundamental management of information and staff and the administrators of the Web site management for members and administrators can add and delete, as well as the administrator password can change settings. Only the administrator to manage part of the 
well-designed for the system to normal operation, only administrators register and sign part of the improvement, companies can have more administrative wage information.

Analysis of Salary Distribution Management

Payroll timeliness is very important for each employee, wages can only be paid by managers according to everyone's job evaluation wage as well as each person's job and salary management.

Analysis of Salary Inquiry Management

Salary search management is one of the most important modules of the system, which is to provide a platform for the exchange of wages or query, that kind of. Every day, employees can communicate with companies via landing, through employee feedback comments, companies can continue to grow. Salary search management is set up for the convenience of site managers to manage and modify, and payroll management component must be a site administrator, normal user login site, is you don't see that part. Salary management will display all information about his pay, and ease of management to manage visitors.

Analysis of Cancellation Management

Analysis of cancellation management is mainly to formulate modules according to the process of websites, and managers can decide whether to cancel according to their own willingness so as to facilitate administrators in operation.

\section{System Design}

The division of website's functional modules is based on users' rights, and one kind of users is the administrator who has the right to manage and enter into the system, that is, they have the right to add, modify and delete employees as well as distribute and inquire the distribution of employees' salary.

Design of Login Module. This module implements the validation before the user enters the system management, user only if the user name, login ID and password are correct can be achieved simultaneously landing, access to the system, and various management actions. If the user enters a username, login identity or password, there is an error, the system will give an error prompt. In order to achieve a secure login, system setup password protection feature, the password entered by the user is displayed as an asterisk. Administrator login process is shown in Fig. 1. 


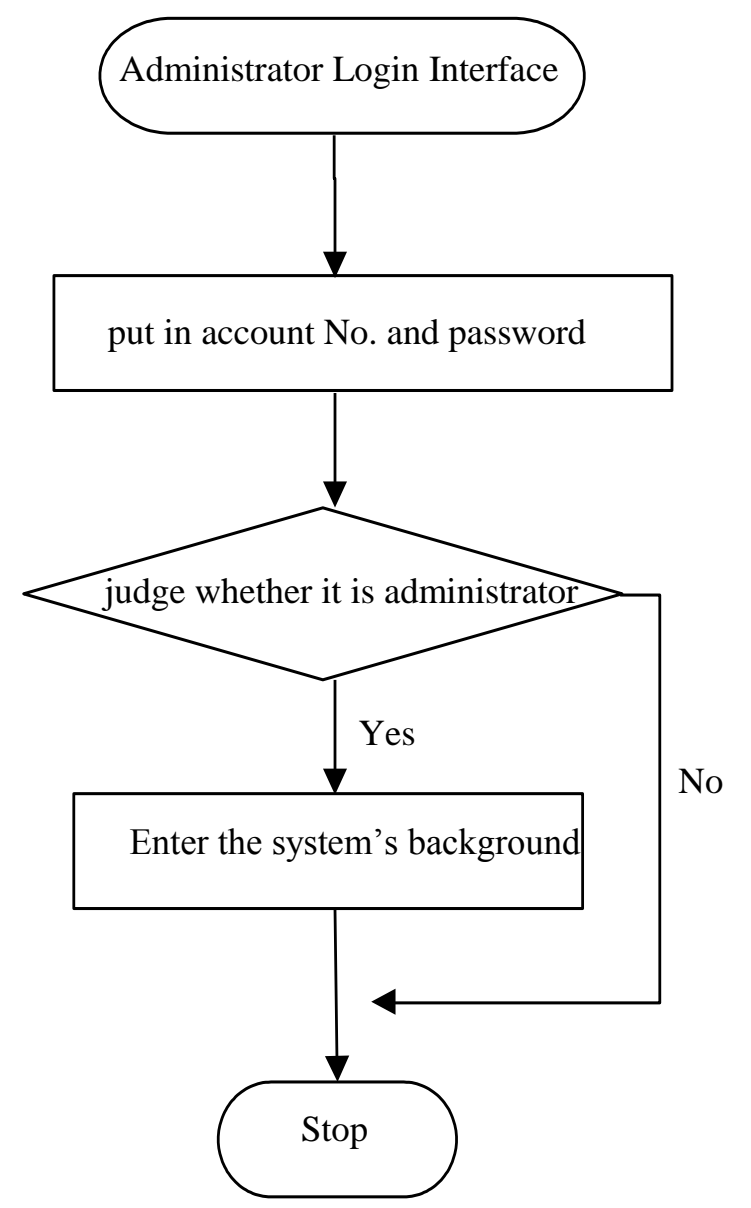

Fig. 1 Process for the access of Administrator

Overall Functions of System. In accordance with industry procedures of the system, the system is mainly divided into the system administrator's management, password management, employee records, payroll management, payroll inquiries, and cancellation information.

Design of Company's Administrator

This section contains six small modules, which are the company administrator's management, password management, employee records, salary distribution, payroll inquiries, and cancellation information module.

Admin management module, it consists mainly of an administrator logged in to the background, and through changes to the back-office company profile module update data in the database, you can call lmnr to the front desk the table displays the payroll administrator to change of content.

Password modules, it consists mainly of an administrator logged in to the background, through to back-end services module of the change data in the database update, calls to the 
front desk after the lmnr table can be displayed when an administrator changes the service content of the project.

Employee file module, it consists mainly of an administrator logged in to the background, recruitment module based on the background of the change data in the database updates, call to the front desk after the lmnr table can be displayed when an administrator changes the job content.

Payroll module, it consists mainly of an administrator logged in to the background, through the contact us module on the background of change data in the database is updated, you can call lmnr to the front desk the table displays the administrator changes contact us content.

Payroll Inquiry module, it consists mainly of an administrator logged in to the background, through the contact us module on the background of change data in the database is updated, you can call lmnr to the front desk the table displays the administrator changes contact us content.

Password Management Design

This module implements a news presentation and management of the company, an administrator user name and password to log into the backend interface, through the backstage News's operations such as add, delete, modify, and entry into the database of company news and current, XW front interface reads the database tables to the stage show news and links.

Design of Employees' File Management

This module consists of two parts, one is the admin part and another is the VIP part.

After the administrator's initial design, you can log into the backend interface for administrators to manage module for administrators to add, remove, and reset the password. Website maintenance and management can have more than one administrator, administrators can additions and deletions and other actions for the other modules, module can also set up multiple administrators manage.

Added part almost is each website essential of part, employees number of how much also in must degree Shang reaction company also performance of bad or website design of bad, Member is above general user of a groups, they can enjoy between administrator and some power among general users. General employees only through managers only can in website Shang browse wage information situation, if found wage assessment appeared errors can timely requests administrator for modify.

Design of Salary Distribution Management

This module implements the product presentation and management of the company, an administrator user name and password to log into the backend interface, through back-product modules operations such as add, delete, modify, and timely entry into the company's product database, $\mathrm{CP}$ front interface reads the database tables to the stage show, and links.

Design of Salary Inquiry Management

This module implements the management of company payroll queries, administrators through a user name and password to log into the backend interface, deleting and browsing through the mail spooler module, mail module is made up of front entry to the database, background removed, he directly reflect the ideas of members and customers, so the message board for the portal is very necessary. 


\section{Design of Database Conceptual Structure}

Conceptual structure is an abstraction of the real world, that is, of actual people, things, and concepts for human processing, extracting common features of interest, ignoring non-essential details and concept accurately describes these features in a variety of.

Entities have developed according to the needs analysis: Administrator information entities in the entity, employee information, profile information entities, payroll information, and cancellation information entities.

Each entity is in reality object abstraction of each of two or more possible to derive a relationship between entities. The e-r diagram below is each entity.

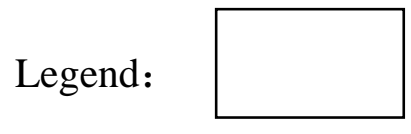

Represents Properties

\section{Represents Entity}

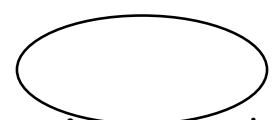

Represents Relationship

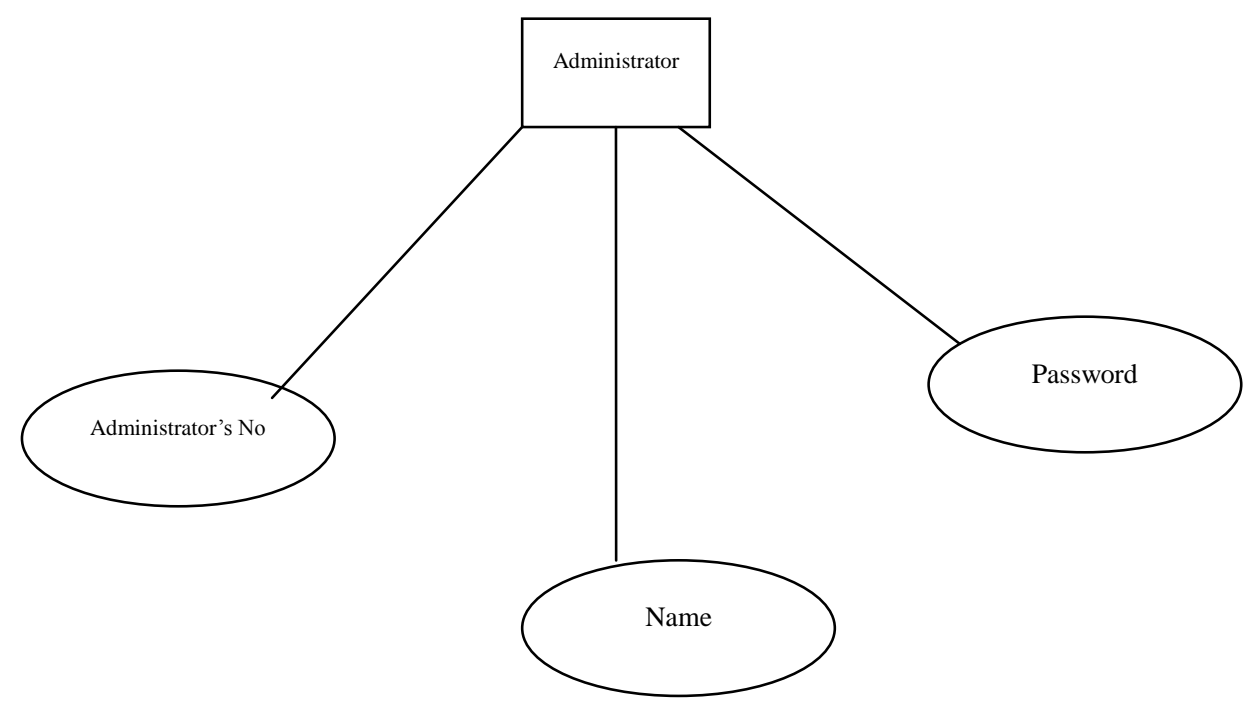

Fig. 2 Entity Diagram of Administrator's Information

Entity diagram of Employees' Information is as shown in Fig. 3 


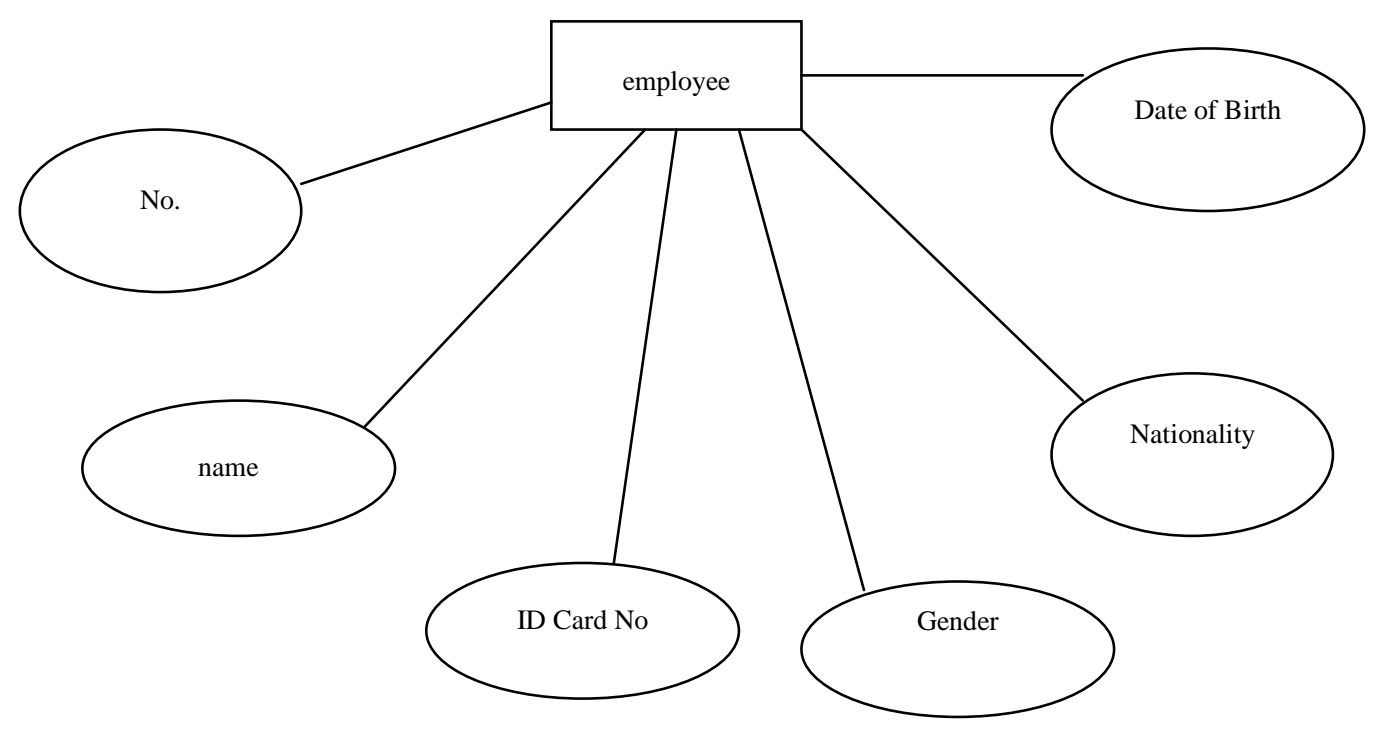

Fig. 3 Entity Diagram of Employees' Information

Entity Diagram of Products' Information is as shown in Fig. 4

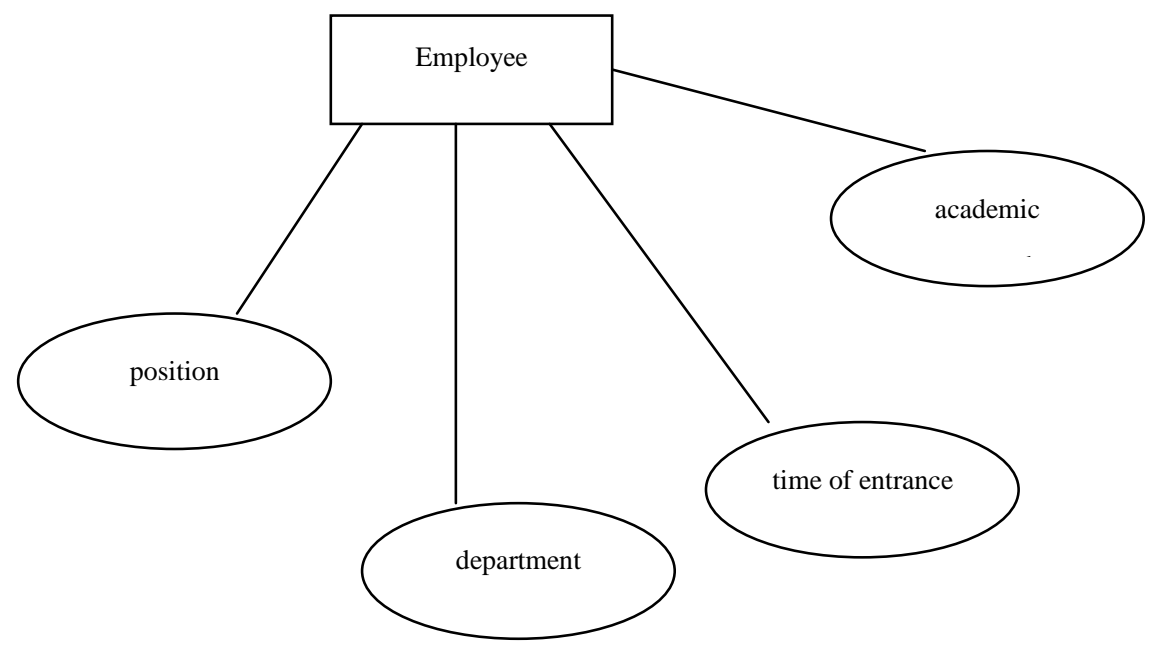

Fig. 4 Entity Diagram of Products ' Information

Entity Diagram of Salary Distribution Information is as shown in Fig.5

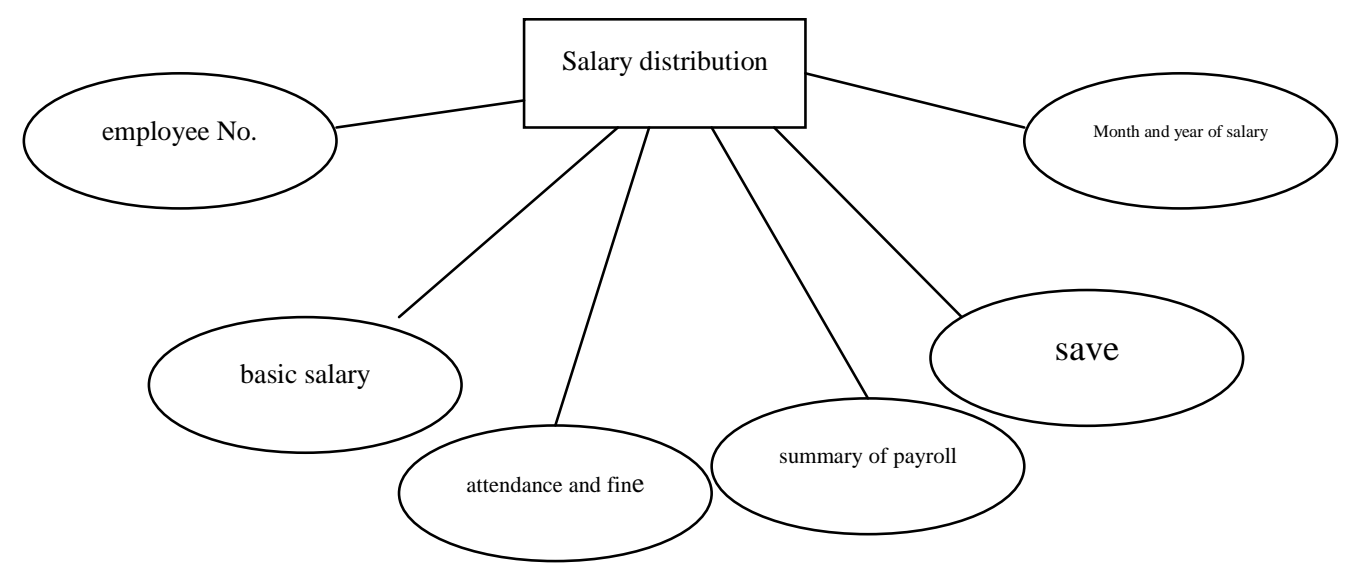

Fig.5 Entity Diagram of Message Board Information 
Entity diagram of salary inquiry information is as shown in Fig. 6

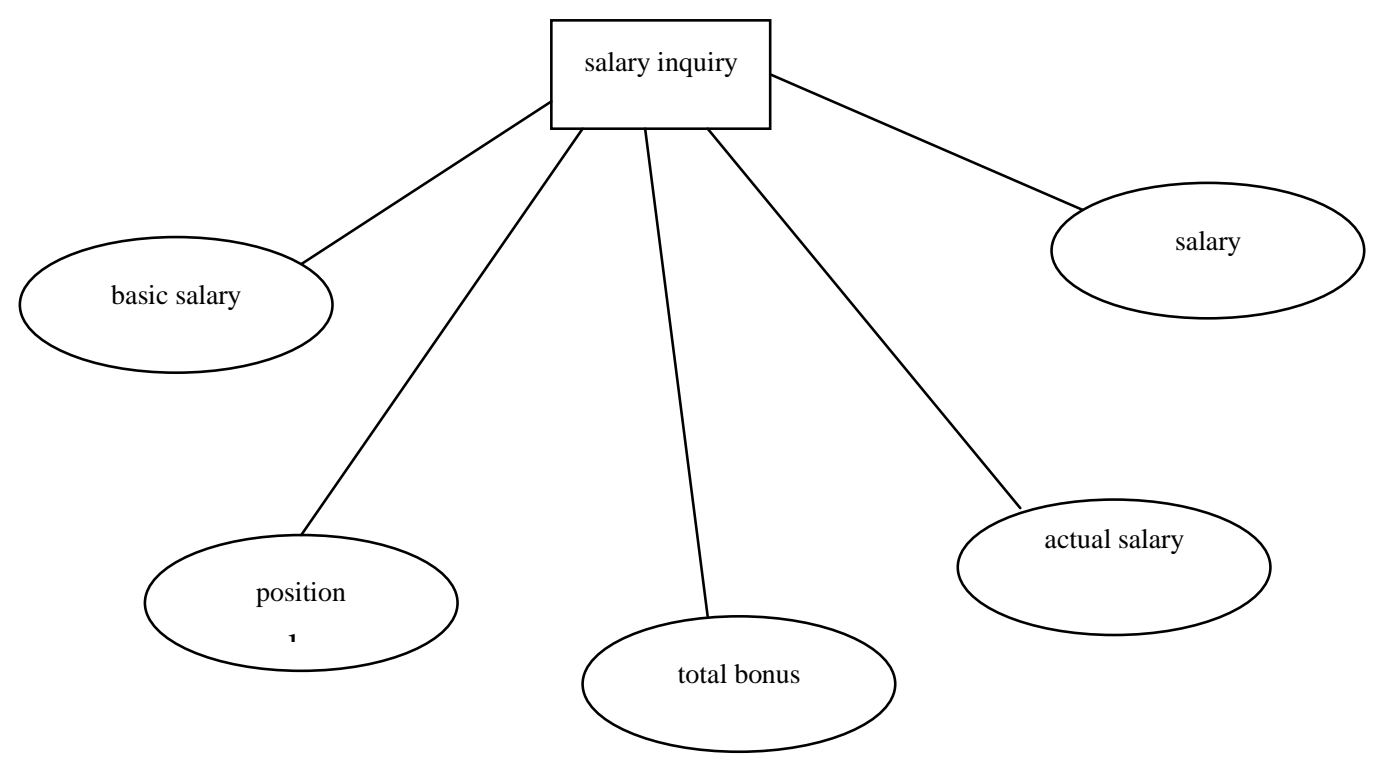

Fig. 6 Entity Diagram of News Information

\section{Test}

Two basic methods can be used for identify the tested cases, that is, functional test (black-box test) and structure test (white-box test). This test mainly adopts functional test.

Basic opinions of functional test is that any program can be seen as the domain of the input values are mapped to the output range of functions.

Test Plans and Key Points. The essence of software test is to determine a group of test cased according to the contents. Before discussion, I would first list plans and key points of each module to be tested.

Key Points of Dictionary Maintenance Test

Connection of database: normal with a lack of database document, and the external system is abnormal;

System set and acquisition: normal and external system is abnormal;

Response to user's input: legal input that can normally adjust sub-modules;

Illegal input, and whether the system can identify and make response (give warning);

Whether the system can timely respond to the abnormal condition of sub-module.

Key Points of System Management Test

Normal operation procedure of modules;

Test data input by users, including testing whether the data are reasonable and legal;

Database operation'

Response at abnormal connection to database.

Key Points in Testing News Management Module

When data base is normally connected;

Put in reasonable and legal parameters;

Parameters are irrational;

Parameters are illegal; 
Database connection is abnormal;

Database is abnormal.

Test Cases. Test cases are for a specific purpose (such as study path or specific procedures to verify compliance with a specific requirement) designed to test data and related test procedures for a particular collection, or effectively detect software defects of the smallest unit test execution.

According to the test points are given in the previous section, and because the test is not exhaustive. So we use equivalence partition method for testing on library management system. It will not be an exhaustive testing process for classification, thus ensuring the representativeness and completeness of test cases design.

Test Results and Conclusion. Test Results

We give corresponding test results according to the order to test samples.

And test results of dictionary maintenance module is as shown in Table 1.

Table 1 Test Results of Dictionary Maintenance Module

\begin{tabular}{|c|l|}
\hline Identifier & C1 \\
\hline Test Results & Normal operation without any abnormality. \\
\hline $\begin{array}{c}\text { Deviations from } \\
\text { Expectation }\end{array}$ & None \\
\hline Noted Problem & Dictionary maintenance module has passed the functional test \\
\hline
\end{tabular}

Test results of system management module are as shown in Table 2

Table 2 Test Results of System Management Module

\begin{tabular}{|c|l|}
\hline Identifier & C2 \\
\hline Test Results & The system can give correct information when putting in information but not the title. \\
\hline $\begin{array}{c}\text { Deviations from } \\
\text { Expectation }\end{array}$ & $\begin{array}{l}\text { Complete information should be in put while adding information, such as title and } \\
\text { contents, etc. }\end{array}$ \\
\hline $\begin{array}{c}\text { Noted Problem } \\
\text { Functions of system management module remain to be improved. }\end{array}$ \\
\hline
\end{tabular}

Test results of news management module are as shown in Table 3

Table 3 Test Results of News Management Module

\begin{tabular}{|c|l|}
\hline Identifier & C4 \\
\hline Test Results & Normal operation without any abnormality. \\
\hline $\begin{array}{c}\text { Deviations from } \\
\text { Expectation }\end{array}$ & None \\
\hline Noted Problem & News module has passed the functional test \\
\hline
\end{tabular}

\section{Conclusions}

This design basically meet basic needs of media online system, realize the convenience of users and administrators to manage convenience, on the interface to accomplish simple, practical, and try to be in operation to meet the habit of users, is not perfect in many ways, some functions without a good grasp on the global, such as some functions can be defined in a file, the specific page requires direct reference again, SQL statement execution effect also has the problem of efficiency is not high, about media online all the operations on a page, there 
have been some confusion, program changes, test is very bad, and so on. If you use SQLServer2008 and Microsoft Visual Studio 2010 program running speed may be higher.

Database connection is the main problem (such as a SqlDataSource control contains a data connection object that can connect to a SQL Server database also contains data used for SQL Select, Update, and Delete statements command object), the use of GridView, DataList, and Repeater controls (both can display the data in different ways, each control also supports additional features, including sorting, paging, Editing data records, inserting new data records, and so on) and, in addition, ListBox and DropDownList controls, binding, final issues are resolved.

\section{Acknowledgements}

This work was financially supported by project of Technology Department of Jiangxi Province [No 20143BBM26048] and project of Jiangxi University of Technology [No. xtcx201312].

\section{References}

[1] Dai Zongyou, Zhang Wurong, Yang Hui. C\# Program Design Training [M]. Tsinghua University Press, 2011:24-25.

[2] Kensili-hudgins, C\# Experience Handbook [M]. Qinghua University Press, 2009:28-29.

[3] Visual C\# 2005 from Beginning to Proficiency, Qinghua University Press, 2009: 33-35

[4] Zhou Hongan. Learn C\# in 21 Days [M] Electronic and Industrial Press, 2009:17-18

[5] Sai Kuichun, Song Kun, Zhao Zhiyong, etc. C\# Information System Development Instance Selection [M]. Mechanical Industry Publishing House, 2010:29-30

[6] Wu Junliang. C\# Program Application and Development Courses [M]. Mechanical Industry Publishing House, 2010:40-44.

[7] Lin Qi. Database Programming and Cases. Release Department of China Electric Power Press, 2008:53-54

[8] Kang Xiangshun, Zhang Xiaogang, Liu Liang. C\# Program Cases Development Selection [M]. Publishing House of Electronics Industry, 2008:10-11

[9] Yuan Pengfei. SQL Server 2000 Database System Management [M]. People's Pose Press. 2008:56-58

[10] Larsen Microsoft SQL Server 2000 Reporting Services[M].清华大学出版社, 2009: $67 \sim 68$

[10] Larsen Microsoft SQL Server 2000 Reporting Services[M]. Tsinghua University Press, 2009:67-68

[11] Matthew MacDonald.Bedinning ASP.NET 4.0 in C\#2010[M].Apr ess,2010: 26〜27 